\title{
La interpretación de los derechos fundamentales por parte del Tribunal Constitucional: una argumentación en términos de razonabilidad
}

\author{
Mercedes Galán JuÁREZ
}

Universidad Rey Juan Carlos

RESUMEN. Este artículo trata sobre uno de las principales materias de la filosofía jurídica, la interpretación del derecho, y más concretamente, la interpretación de las normas de derechos humanos contenidos en la Constitución Española. Hay dos preguntas centrales que está conectadas entre sí: la primera se refiere a por qué es necesario interpretar las normas de derechos humanos y la segunda plantea cómo interpretar esas reglas de tal manera que el resultado de ese razonamiento conduzca al principal objetivo de toda interpretación jurídica: la búsqueda de una solución justa. Mi tesis es que la interpretación jurídica de los derechos humanos supone mucho más que una mera aplicación mecánica de las normas o principios que existen en una situación social particular. El razonamiento jurídico implica una argumentación en términos de razonabilidad hecha a partir de la ponderación de las reglas que contienen derechos -cuando actúan como principiosen conflicto, de tal manera que el intérprete tenga la seguridad que no resulta ninguna injusticia de sus actuaciones. Las principales razones para tal entendimiento son el respeto a la autoridad y el valor de la continuidad del derecho, especialmente el primero. En este sentido, es clara la influencia de la Jurisprudencia Analítica en el tema de los Derechos Humanos y de los derechos en general. Muchos de los estudios que versan sobre ellos están influidos
ABSTRACT. This article deals with one of the mayor issues in legal philosophy, that is to say the interpretation of the law, and more precisely, the interpretation of rules of human rights contained in the Spanish Constitution. There are two central questions which are connected: The first is why it is necessary to interpret the rules of human rights and the second is how to interpret those rules so that the result will lead to the main purpose of the legal reasoning: to search for a just solution. My thesis is that legal interpretation of human rights includes far more than a pure and mechanical application of norms or principles in a given social situation. It implies a reasonable argumentation made from the balancing of the rules containing rights -understood as principles- in conflict so that the interpreter is sure that no injustice results from his proceedings. The main reasons for understanding interpretative legal reasoning in such a way are respect for authority and value continuity, specially the first. In this sense the influence of Analytical Jurisprudence on the issue of Human Rights and rights in general is clearly visible. Many studies on rights are influenced by or directly formed by means of analytical patterns of thought, as is the case in the approaches of J. Raz. 
o están directamente elaborados a partir de los modelos de pensamiento analítico, como es en el caso de las aportaciones de J. Raz.

Palabras clave: Interpretación jurídica, Razonamiento jurídico, Hermenéutica, Derecho, Derechos humanos, Jurisprudencia Analítica, Autoridad, Valores, Principios, Justicia, Racionalidad.
Key words: Legal interpretation, Legal reasoning, Hermeneutics, Law, Human rights, Analytical Jurisprudence, Authority, Values. Principles, Justice, Rationality.

\section{Introducción}

El tema de la interpretación del derecho, en general, representa una de las materias que todo jurista, más o menos dedicado a la investigación sobre el derecho, ha abordado en su carrera profesional. Al jurista que está más vinculado con la práctica del derecho le afecta directamente, en la medida en que el éxito de las pretensiones que desea hacer valer dependerá en parte del resultado de su trabajo argumentativo. Al científico del derecho, más centrado en dilemas teóricos, también le compete puesto que deberá aportar propuestas que permitan entender el derecho como una realidad unitaria y coherente. En uno y otro caso, es un tema que va intrínsecamente unido al quehacer diario del jurista y no sólo en los tiempos presentes sino desde que existe el derecho. Derecho e interpretación nacen y se desarrollan a la vez. No es posible el uno sin la otra.

A lo largo de las páginas siguientes intentaré aportar una modesta contribución a la teoría de la interpretación, que ha sido especialmente fructífera gracias, entre otros, a los trabajos de los filósofos del derecho. Dicha contribución estará centrada en una realidad jurídica particular: las normas de derechos fundamentales y a su interpretación por parte del Tribunal Constitucional a través de una argumentación en forma de razonabilidad.

Entendemos que el estudio de la interpretación de los derechos humanos pasa necesariamente por dilucidar qué se entiende en primer lugar por interpretación, en general, e interpretación jurídica, en particular. De hecho, no falta quien justifica la necesidad de establecer la noción de interpretación con el fin de determinar el valor de verdad de enunciados habitualmente usados por los operadores jurídicos ${ }^{1}$. A esta pregunta le sigue necesariamente la reflexión en torno a qué nos estamos refiriendo cuando hablamos de interpretación de los derechos fundamentales. Asimismo es importante determinar porqué interpretar es esencial para entender el concepto

${ }^{1}$ Moreso, J. J.: La indeterminación del derecho y la interpretación de la Constitución. Centro de Estudios Políticos y Constitucionales. Madrid, 1997, p. 17. De hecho, este autor articula a lo largo de los cuatro primeros capítulos una "imagen del Derecho según la cual la Constitución ocupa un lugar de preeminencia para determinar el valor de verdad de las proposiciones jurídicas". 
mismo de interpretación pero, sobre todo, para encontrar razones que den sentido a la actuación del intérprete y le guíen cómo y para qué debe interpretar. De esta forma, nuestro trabajo en el marco de la Filosofía del Derecho explica la dimensión teleológica que inevitablemente se vislumbra en toda labor interpretativa y que la aparta de una actuación puramente silogística.

\section{1. ¿Qué significa interpretar?}

La palabra interpretación, al igual que otros muchos términos que se emplean tanto en el lenguaje coloquial como en el jurídico, tiene varias acepciones, siendo necesaria la determinación de la más adecuada al objeto sobre la que se aplica. Es un término que se proyecta a realidades diversas y por ello su sentido varía en función de ellas. Así, por ejemplo, se habla del intérprete como el que ejecuta una obra musical, el que traduce de una lengua a otra, el que representa una obra teatral o cinematográfica, etc.

Cuando los principales diccionarios y enciclopedias jurídicas explican la voz interpretación no hacen referencia a la interpretación del derecho en sentido general, sino que concretan en una realidad jurídica normativa. Así tratan directamente de la interpretación de la ley o la interpretación de la norma jurídica, sobre todo desde la perspectiva civil ${ }^{2}$, o bien especifican los diferentes tipos de interpretación al uso: doctrinal, extensiva, gramatical, histórica, judicial, lógica, restrictiva, sistemática, unilateral, etc. ${ }^{3}$ De hecho, más que de interpretación se habla de interpretar como la actividad que consiste en "explicar o declarar el sentido de los textos jurídicos, especialmente de aquellos que están faltos de claridad"4, la "operación o actividad dirigida a la búsqueda del sentido y significado de la norma aplicable al caso"5, "la aprehensión del significado de la norma jurídica, con el fin de aplicar la misma a la realidad social a la cual se refiere"6 o la búsqueda de "entre los varios entendimientos posibles de una regla de Derecho" de aquella opción "que mejor se acomode a los dictados constitucionales"7, en este caso, en relación con la interpretación "conforme a la Constitución”.

${ }^{2}$ Fundación Tomás Moro: Diccionario Espasa Jurídico. Editorial Espasa Calpe, Madrid, 2001, p. 845; Ribó Durán, L.: Diccionario de Derecho. Tomo II, Editorial Bosch, Madrid, p. 797, se refiere a la "Interpretación jurídica" en el marco del "Derecho civil y de las personas".

3 Ribó Durán, L.: Diccionario de Derecho. Tomo II, Editorial Bosch, Madrid, p. 797; Gómez de Liaño, F.: Diccionario Jurídico. (5 a edición), Editorial Forum, p. 183; Fonseca-Herrero Raimundo, J. I. e Iglesias Sánchez, M. J.: Diccionario jurídico. Editorial Colex, Madrid, 2005, p. 250.

Martínez Marín, J., Martín Martín, J. y Ávila Martín, C.: Diccionario de términos jurídicos. Granada, 1994, p. 235. p. 235 .

${ }^{4}$ Martínez Marín, J., Martín Martín, J. y Ávila Martín, C.: Diccionario de términos jurídicos, op. cit.,

${ }^{5}$ Fonseca-Herrero Raimundo, J. I. e Iglesias Sánchez, M. J.: Diccionario jurídico. op. cit., p. 250.

6 Fundación Tomás Moro: Diccionario Espasa Jurídico, op. cit., p. 845

${ }^{7}$ Enciclopedia jurídica básica. Volumen III, Civitas, Madrid, 1995, p. 3681. 
De entre todas estas afirmaciones veremos a lo largo de este artículo, en qué medida la última se ajusta más al propósito de nuestro tema, estando vinculada además con la idea de que "la pretensión normativa de los textos jurídicos no se dirige tanto a una comprensión -correcta, reflexiva y que sea un fin en sí mismadel texto en cuanto tal, sino más bien a un actuar justo" puesto que "en el ámbito del derecho, la comprensión del texto se configura como un 'actuar práctico""8.

El término interpretación nos remite a otras palabras para aclarar su contenido: comprensión, argumentación, razonamiento, motivación o integración. Sin embargo, no resulta tan evidente en el ámbito jurídico que algunos de estos términos sean más concretos que el general de interpretación. Así por lo menos lo manifiesta quien señala que "dentro de la argumentación aparece la interpretación. La realización interpretativa nutre en gran parte la argumentación, pero no se identifica plenamente con ella, (...) salvo que por interpretación, adoptado en sentido amplio del término, se entienda todo el devenir intelectual que conduce a la aplicación de la norma. Una cosa es que en la interpretación influyan otros procederes argumentales y que todos los elementos del razonamiento se hallen en indisoluble interrelación y mutua influencia, y otra que puedan conceptualmente confundirse. La argumentación es un instrumento al servicio de la interpretación (...) y representa el paso de la racionalidad abstracta a la racionalidad concreta. (...) Así pues, como elementos y, en su caso, operaciones distintas aparecen: los materiales para la interpretación, la interpretación propiamente dicha utilizando los criterios interpretativos que suministran esos materiales mediante directivas interpretativas, la argumentación jurídica integrada por la argumentación interpretativa y por el resto de la argumentación (...) y el razonamiento jurídico como modo de proceder dentro de la argumentación según la concepción del Derecho que se tenga"9.

No coincidimos plenamente con quien formula estas afirmaciones porque, además de percibir una cierta contradicción entre la que señala que dentro de la argumentación aparece la interpretación y la que sostiene que la argumentación es un instrumento al servicio de la interpretación, entendemos que sería ésta última la que se acercaría más a nuestra concepción de la interpretación. Ésta consistiría en la forma genérica de referirse a la actividad que pretende el conocimiento y entendimiento de un texto normativo. El intérprete explica el proceso de ese entendimiento por medio de la argumentación, teniendo en cuenta que el modo de aproximarse al texto se ha tenido que hacer de forma razonable si se quiere cumplir la misión que todo intérprete debe realizar ${ }^{10}$. En este sentido, la

8 Zaccaria, G.: Razón jurídica e interpretación, Civitas, Madrid, 2004, (trabajos compilados por Ana Messuti), p. 59. Cursiva nuestra.

${ }^{9}$ Requena López, T.: Sobre la función, los medios y los límites de la interpretación de la Constitución. Editorial Comares, Granada, 2001. pp. 52 y 54.

10 Hay quien para referirse a la actividad misma habla de hermenéutica - y en concreto de la "hermenéutica filosófica" como perspectiva epistemológica surgida a partir de la crisis del positivismo- especificando que 
labor de intérpretes como son un jurista o un artista es diferente en la medida en que la forma que tiene el artista de manifestar su interpretación de la obra de arte - una partitura, por ejemplo- es a través de su ejecución en un concierto, por ejemplo, mientras que en el caso de un jurista esa interpretación se materializa en la argumentación que diseñe de la realidad interpretada - una norma-. De ahí que podamos concluir que la argumentación es un instrumento al servicio de la interpretación por medio de la racionalidad. En todo caso, el acto de interpretación requiere una comprensión del texto y de la situación que se va a interpretar. Se trata de una labor previa a la interpretación en la medida en que si no se da la primera, no es posible la segunda. Hay autores que, incluso, alaban a quien ha ido todavía más allá del comprender jurídico refiriéndose a un momento inicial que califican como "precomprensión"11. Si queremos interpretar el contenido de un texto pero no comprendemos el significado de las palabras que lo forman porque, por ejemplo, no conocemos el idioma o una de las acepciones lingüísticas de la palabra, tendremos que acudir a un diccionario. Habrá que comprender lo que significa esa palabra o texto para después proceder a interpretarlo y finalmente aplicarlo a la situación concreta. Igualmente podríamos decir de las notas que forman una partitura o de los términos que marcan los matices de su ejecución.

Sin salirnos del ámbito jurídico compartimos la afirmación de que "la comprensión del derecho presupone la comprensión de las modalidades según las cuales el derecho se autocomprende" 12 , de ahí que "el comprender jurídico consista en el análisis, en la revisión y penetración de un esquema proyectivo de significado que se encuentra en el origen de la aproximación al texto y que es rectificable siempre que se revele inadecuado en el curso del proceso de comprensión"13.

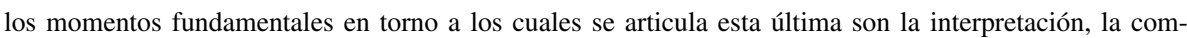
prensión y la potencial aplicación a los casos concretos.: Robles, G.: en el Prólogo del libro de Zaccaria, G.: Razón jurídica e interpretación, op. cit., p. 9. Cursiva nuestra.

${ }^{11}$ Es el caso de G. Zaccaria cuando considera que el mérito de la hermenéutica de J. Esser ha sido el haber incorporado "la precomprensión como momento inicial del comprender jurídico" a "la teoría de la interpretación elevando la descripción del procedimiento de investigación del derecho a un plano epistemológicamente maduro". A esta afirmación añade que "la interpretación jurídica es siempre el fruto de la actividad de un sujeto que comprende y actúa desde dentro de un contexto, partiendo de una precomprensión e insertándose en una praxis y en una comunicación que implican a la comunidad. Sin una pre-inserción en el contexto de la práctica social interesada es imposible tener éxito en la interpretación de los actos y de los comportamientos ajenos. Es gracias a la precomprensión del universo social dentro del cual se producen las acciones como el intérprete puede colocar adecuadamente los eventos externos": Razón jurídica e interpretación, op. cit., p. 389 y 390.

12 Zaccaria, G.: Razón jurídica e interpretación, op. cit., p. 55.

13 Asimismo, esta labor de comprensión, además de ser eminentemente activa en el sentido señalado, demanda también por parte del que la lleva a cabo la capacidad de "completar con el pensamiento la opinión que el legislador quería, a partir de sus momentos, hacer vinculante". De hecho, "interpretar el texto significa también aclarar por qué el legislador ha tomado una determinada decisión: pero ello implica (...) la necesidad de adentrarse en la particularidad de sus elecciones, es decir, de asumir la situación y la 'disposición de conciencia' de un mundo histórico-social. Sólo a partir de la comprensión de los motivos 'racionales-materiales' que hablan a favor de una norma determinada se puede interpretar dicha norma, desarrollarla y volver a formularla, colmar sus lagunas y presentar nuevas propuestas de ley": Zaccaria, G.: Razón jurídica e interpretación, op. cit., p. 53 y 389-391. Cursiva nuestra. 
Es quizás en este último punto en donde la actividad de la comprensión engarza con la interpretación y donde debería proyectar en ella los frutos de su labor. Para haber producido una correcta interpretación se ha tenido que dar la circunstancia de que dicha previa comprensión se haya desarrollado "de acuerdo a reglas intersubjetivamente compartidas" 14 y también que haya tenido en cuenta que si bien debe de ser lo más precisa posible, no debe pasar por alto que "la pretensión normativa de los textos jurídicos no se dirige tanto a una comprensión -correcta, reflexiva y que sea un fin en sí misma- del texto en cuanto tal, sino más bien a un actuar justo" puesto que "en el ámbito del derecho, la comprensión del texto se configura como un 'actuar práctico"'15. Esa precisión del actuar práctico nos remite a uno de los elementos centrales de este trabajo al poner de manifiesto que en ningún caso la labor de interpretación del derecho - o cualquiera de las fases previas o siguientes- sería puramente mecanicista ni se agota en una perfección formal sino que tiene un claro componente finalista en la medida en que la razón de ser de esta actividad será conseguir presentar el derecho más justo posible. Puede que esta afirmación reciba la objeción de que estamos intentando ver en el acto de interpretación no tanto lo que es sino lo que debería ser, y por tanto estamos saltando el terreno de la realidad para situarnos más cerca del plano del deseo. No es ese el caso, más bien lo contrario. Creemos que no se puede hablar de interpretación jurídica en sentido estricto si ésta no ha sido capaz de vislumbrar la relevancia del componente valorativo que subyace en los entresijos normativos. El derecho toma forma en el recipiente de la interpretación y ese recipiente debe estar diseñado con el molde de la justicia. De hecho "las teorías hermenéuticas reconocen e incluyen como factor constitutivo de su propio discurso teórico la importancia e influencia de los elementos valorativos en el procedimiento de individualización del derecho. Su punto fundamental consiste precisamente en reconstruir el procedimiento a través del cual el intérprete llega a la decisión considerada justa, para fundamentar de tal modo, racionalmente, el ámbito práctico de la decisión justa"16.

Si el actuar en busca de lo justo debe ser ineludible en la interpretación jurídica en general, su exigencia se hace todavía más acuciante en el caso de la interpretación de los derechos fundamentales contenidos en la Constitución, a pesar de que se haya señalado que "desde la perspectiva del razonamiento jurídico resulta muy difícil hablar de singularidades en la interpretación constitucional"17. Entendemos que esta afirmación está referida más bien a la utilización de los criterios generales de interpretación jurídica que, en efecto, no quedaría al margen de la interpretación de los derechos fundamentales pero que, en el caso de la

14 Zaccaria, G.: Razón jurídica e interpretación, op. cit., p. 389-390. Cursiva nuestra.

15 Zaccaria, G.: Razón jurídica e interpretación, op. cit., p. 59. Cursiva nuestra.

16 Zaccaria, G.: Razón jurídica e interpretación, op .cit., p. 27.

17 Requena López, T.: Sobre la función, los medios y los límites de la interpretación de la Constitución, op. cit., p. 52. 
Constitución "se alzaprima por la proliferación de normas de carácter abierto, valores y principios a escrutar y concretar, y por la trascendencia de los contextos sistémico y funcional". De ahí que "el criterio literal es un punto de partida ineludible, pero en la interpretación de la Constitución los criterios sistemático y teleológico tienen una gran importancia"18. Es más, el Tribunal Constitucional "que ha rechazado siempre 'interpretaciones meramente literales' (Sentencia del Tribunal Constitucional 18/1982, fundamento jurídico $2^{\circ}$ ) y que ha buscado en todo caso una interpretación lógica y sistemática (Sentencia del Tribunal Constitucional 25/1983, fundamento jurídico $3^{\circ}$ ), ha procurado huir de la formulación de reglas generales o, por lo menos, de mayor generalidad de la indispensable para cada caso (Sentencia del Tribunal Constitucional 40/1982, Fundamento jurídico $2^{\circ}$ ), y ha construido las necesarias nociones y principios hermenéuticos partiendo siempre de la lógica inmanente a la Constitución"19. Precisamente esa "lógica inmanente a la Constitución" nos remite a los valores y principios que la informan. Este razonamiento puede tener una cierta apariencia de circularidad en la medida en que el Tribunal Constitucional tiene como fuente de su actividad los dictados de la propia Constitución y en concreto, la lógica constitucional teñida de valores y principios. A su vez, el propio Tribunal Constitucional actúa formulando y construyendo resoluciones impregnadas de esos valores y principios en su intento de huir de respuestas generales y abstractas vacías de contenido material. Sin embargo, consideramos que lejos de la posible circularidad expuesta, lo que encontramos en la actuación del Tribunal Constitucional es una coherencia propia de su misión, centrada fundamentalmente en lograr una justicia constitucional acorde con un actuar práctico. En definitiva, se trata de reforzar la idea de que el Tribunal Constitucional interpreta los derechos fundamentales teniendo en cuenta el fin para el que realiza su función - materializar el sentido concreto de los derechos proclamados en la Constitución- y la razón de la proclamación de los derechos fundamentales - conseguir una convivencia marcada por la máxima expansión del ejercicio de derechos y libertades necesarios para la convivencia pacífica en una sociedad democrática.

Volviendo de nuevo a las diferentes concepciones de la actividad interpretativa, no se descarta entender que "toda interpretación jurídica (...) es argumentación con vistas a un litigio, actual o potencial, pero ello no significa (...) que sus sujetos sean, en exclusiva, los órganos jurisdiccionales. A éstos les corresponde, ciertamente, la facultad de decir el derecho definitivamente (...) y a uno de entre ellos - al Tribunal Constitucional- la condición de 'intérprete supremo de la Constitución (...), lo que se traduce en el singular valor de la jurisprudencia constitucional, no, desde luego, en una exclusividad o monopolio de este órgano para

${ }^{18}$ Requena López, T.: Sobre la función, los medios y los límites de la interpretación de la Constitución, op. cit., p. 55

${ }_{19}$ González Rivas, J. J.: La interpretación de la Constitución por el Tribunal Constitucional (19802005). Civitas, Madrid, 2005, p. 31. Cursiva nuestra. 
la interpretación de la Constitución: la norma fundamental impregna todo el ordenamiento y por ello los llamados tribunales 'ordinarios' son jueces tanto de la 'legalidad' como de 'la constitucionalidad'. Cualesquiera otros sujetos jurídicos -órganos públicos o particulares- la interpretan también al realizarla, al cumplirla y al hacerla cumplir. ${ }^{20}$ Recordemos en este sentido que el artículo 9.1 de la Constitución Española no sólo señala que son los poderes públicos los que están sujetos a la Constitución y al resto del ordenamiento jurídico, sino que son los ciudadanos sus primeros destinatarios. Asimismo, y por medio del ars interpretandi que realizan los juristas, se pone de manifiesto "la capacidad de la sociedad para dar forma a través del jus a un orden social" 21 . Serán por tanto todas las fuerzas sociales en su conjunto las que, a través de su actuación dirigida al cumplimiento de la Constitución, las que logren una convivencia de acuerdo con unos valores y principios aceptados en un contexto de pluralismo político.

\section{2. ¿Por qué es necesaria la labor de interpretación?}

La pregunta acerca de los métodos de interpretación usados en el derecho es una de las cuestiones principales que estudian quienes se adentran en la problemática de la interpretación del derecho; no ocurre lo mismo en relación con la pregunta de por qué interpretar, sobre la que no centran su atención de forma prioritaria. Sin embargo, esta cuestión es esencial no sólo para conocer las razones que justificarían dicha interpretación, sino que conduce a la pregunta de cómo llevarla a cabo, no menos relevante 22 .

Creemos que las clásicas justificaciones de que el derecho contiene normas generales que hay que aplicar a un caso concreto o la afirmación de que el derecho está integrado por normas y que, como tales, tienen que ser interpretadas para ser aplicadas, no aportan por sí solas, una solución definitiva a la pregunta que venimos planteando. Tampoco porque exista un mandato del legislador que establezca la obligación inexcusable que tienen los jueces y tribunales de resolver todo asunto de que conozcan, sería motivo suficiente que colmara nuestra disquisición. Si bien a lo largo de las líneas siguientes abordaremos lo que cada una de estas razones aporta, adelantamos nuestra posición sosteniendo que estas razones, y otras que se pudieran esgrimir, no son triviales y que si se consideran como compartimentos estancos no se logra dar una respuesta satisfactoria al problema. Solamente cuando todas y cada una de estas respuestas apuntan a un motivo que va más allá de la mera praxis jurídica o del mandato legislativo, cobran verdadero sentido. En concreto, entendemos que no deberían perder de vista que la realización de un derecho lo más justo posible debe ser el motor de su actividad. Es,

\footnotetext{
${ }^{20}$ Enciclopedia jurídica básica. Volumen III, op. cit., p. 3690. Cursiva nuestra.

21 Zaccaria. G.: Razón jurídica e interpretación, op. cit., p. 383.

22 Raz, J.: “Why Interpret?", en Ratio Iuris, 9, 1996, pp. 349-363, en concreto pp. 349 y 351.
} 
por tanto, la luz de la justicia, la que da sentido esta tarea. Hay quien incluso va más allá de estas palabras señalando que "la razón por la que hay que interpretar es el respeto moral que debemos al objeto de la interpretación, es decir, al derecho y a sus fuentes"23. En efecto, esta afirmación condensa y, quizás, completa nuestra posición porque no sólo mira al resultado de lo interpretado - un derecho lo más justo posible- sino que pone en el propio derecho -lo interpretado- la semilla de lo más justo posible y, por tanto, presupone un elemento moral integrado en lo que se va a interpretar. Como resultado de ello es posible hablar de una buena interpretación, en la medida en que el intérprete sea capaz de darnos una visión de lo que ha interpretado de forma que en ella se refleje el espejo de los valores y principios a los que sirve 24 .

Adelantada nuestra posición, abordaremos a continuación cada una de las respuestas anunciadas:

2.1. De las definiciones expuestas en el epígrafe anterior, podemos extraer elementos que son comunes a todo acto de interpretación jurídica: existe un sentido de la norma que hay de explicar para poder aplicarla. Ésta sería la primera razón que justificaría la labor de interpretación. De ahí que si no se interpreta una norma, no se puede aplicar de forma que quede garantizado su sentido y significado, llegando a afectar a la correcta aplicación de la misma. Si a esto se añade que hay textos que están faltos de claridad o que existe una realidad social particular a la que hay que prestar especial atención, o que no existe respuesta jurídica al problema y, por tanto, hay que extraerla de entre las existentes, la tarea se torna inexcusable $^{25}$. En todo caso la labor interpretativa ha formado parte de la práctica cotidiana del trabajo de los juristas durante siglos, sea para explicitar el sentido oscuro o no suficientemente determinado de las disposiciones normativas, sea para aclarar lar relevancia jurídica de determinados hechos 26 .

Sin embargo, entendemos que la tarea interpretativa es independiente de la posible oscuridad de lo interpretado porque es una labor que necesariamente se realiza cuando se aplica una norma. De hecho, no sólo se interpretan las normas cuyo efecto es difícil de precisar a partir de su lectura porque contenga términos imprecisos o porque sea difícil determinar su alcance. Todas las normas, sin excepción, necesitan de un acto de interpretación para darle una forma concreta. Ahora bien, "el hecho de que reconozcamos que la interpretación es central en la práctica del derecho, no resuelve el problema teórico de por qué la interpretación

23 Raz, J.: "Why Interpret?", op. cit., p. 359.

${ }^{24}$ En este sentido, J. Raz equipara el derecho al arte en el sentido de que "ambos están hechos para ser interpretados". También en los dos casos resalta cómo los grandes intérpretes son lo que nos hacen ver el trabajo interpretado con una nueva luz: "Why Interpret?", op. cit., p. 357.

${ }_{25}$ De hecho G. Zaccaria ha puesto de relieve cómo "la hermenéutica jurídica supone que recientemente se ha asumido el carácter crucial de la interpretación, que por otra parte constituye de siempre un momento ineludible de cualquier actividad jurídica": Razón jurídica e interpretación, op. cit., p. 354.

26 Zaccaria, G.: Razón jurídica e interpretación, op. cit., p. 353. 
es tan importante. Es más, la respuesta a esta pregunta no se puede limitar a señalar que las reglas jurídicas son reglas generales y que se usan para resolver problemas particulares, porque en muchas prácticas sociales la necesidad de aplicar reglas generales a casos particulares no hace que la interpretación sea tan importante como en el derecho (consideremos, por ejemplo la 'interpretación' de las reglas de juego). Por tanto, debe haber algo especial acerca del derecho que lo hace tan dependiente de la interpretación"27. Entendemos que es en esa aplicación en donde cobra verdadero sentido y significado lo interpretado. No en vano, se ha señalado acertadamente que "no existe de antemano el derecho sobre el cual se ejercería después la función interpretativa, sino que el derecho mismo es resultado de la interpretación" 28 . En sentido parecido es entendida la posición de Dworkin cuando afirma que la interpretación no es algo que algunas veces hacen los jueces y los tribunales, sino que es en cierta medida constitutivo de derecho. Tradicionalmente no, pudiera pensarse que la interpretación es una actividad específica dirigida a entender una norma o a aplicarla a un caso particular. Esta perspectiva parece implicar que existen primero las normas jurídicas y segundo que tienen que ser interpretadas y aplicadas. La tesis de Dworkin del derecho como un concepto interpretativo desafía este punto de vista. No menos relevante es la posición de Raz cuando sugiere que algo hay que aprender acerca de la naturaleza del derecho del hecho de que la interpretación juegue tal crucial papel en la decisión judicial29. Quizás una de las cosas que haya que aprender es que "antes del proceso no se puede hablar de un objeto del proceso mismo, y que dicho objeto sólo en el curso del proceso va adquiriendo sus contornos precisos. (...) No se da la 'cosa' derecho, sino que se dan prácticas interpretativas específicas de quienes participan en las prácticas mismas y contribuyen a definir la identidad de éstas"30. Es más, no se trata de una labor meramente teórica, sino que tiene una clara dimensión práctica, hasta el punto de que es en esa praxis en la que se adquiere el verdadero conocimiento del derecho, no desde la mera especulación teórica. De ahí que también en el ámbito de la ciencia jurídica se afirme que "el jurista puede conocer el derecho solamente practicándolo, y no en formas meramente reflexivas; el derecho no es un 'objeto' para ser mirado ab externo, sino praxis, curso de acción que gradualmente se va desarrollando y precisando en su identidad"31. Es en este sentido donde se ubica la hermenéutica, que "abre con efi-

27 Atria, F. y MacCormick, N.: Law and Interpretation. Ashgate Darmouth, 2003, pp. XI y XII (Introducción).

${ }^{28}$ G. Robles en el Prólogo del libro de Zaccaria, G.: Razón jurídica e interpretación, op. cit., p. 9. Cursiva nuestra.

29 Atria, F. y MacCormick, N.: Law and Interpretation, Op. cit., XI y XII (Introducción). Cursiva de los autores.

${ }^{30}$ Zaccaria, G.: Razón jurídica e interpretación, op. cit., p. 50 y 51. Cursiva del autor.

31 Referido por G. Zaccaria en Razón jurídica e interpretación, op. cit., p. 55 remitiéndose a F. Viola: "Ermeneutica e diritto. Mutamenti nei paradigmi tradizionali della scienza giuridica", en Nicolaci (a cargo de), La controversia ermeneutica. Jaka Book, Milán, 1989, p. 76. Cursiva del autor. 
cacia la ciencia jurídica a la dimensión de la racionalidad argumentativa, pero sobre todo a la dimensión práctica"32.

Es en el ámbito de los derechos fundamentales en donde estas reflexiones se hacen más evidentes en la medida en que el alcance de su contenido se configura no sólo a través del texto constitucional ni en las leyes orgánicas que los desarrollen, sino en la forma que finalmente adopten en cada caso y, especialmente, cuando se tienen que articular con otros derechos fundamentales. Así, por ejemplo, el artículo 18.1 de la Constitución Española que proclama el derecho al honor, a la intimidad personal y familiar y a la propia imagen necesita de su aplicación a una realidad para configurar su verdadero efecto, que en todo caso será "dependiente de las normas, valores e ideas sociales vigentes en cada momento". Por tanto, lo que sea cada uno de los derechos proclamados en este artículo vendrá determinado por la interpretación que de ellos haga, en este caso el Tribunal Constitucional, que además de atenerse a la literalidad de la ley, deberá tener en cuenta, en lo que al derecho al honor se refiere, "las circunstancias concretas en que se producen los hechos y las ideas dominantes que la sociedad tiene sobre la valoración de aquél"33.

2. 2. Otra razón que justificaría la interpretación de los textos jurídicos la encontramos en la idea de autoridad, si bien cobrará diferente significado dependiendo de la perspectiva desde la que se enfoque:

a) Desde una posición que podríamos considerar contraria a defender la idea de autoridad a la hora de aducir razones para la interpretación, destacaríamos las siguientes consideraciones:

- La afirmación de la "insuficiencia que caracteriza al discurso jurídico fundado en meras "razones de autoridad" y ello en un doble sentido: en primer lugar porque el hecho de que una norma sea válida por haber sido elaborada siguiendo un procedimiento establecido por el propio derecho no garantiza que su adecuada operatividad jurídica esté a salvo. De ahí que se abogue por un espacio para la idea de una teoría 'material' (que tenga en cuenta el 'contenido') del derecho, consciente de la exigencia de dejar atrás de una vez por todas las insuficiencias de una razón jurídica formal, técnica, funcionalista" 34 .

- La afirmación de que debido a la división de poderes que marca a las culturas jurídicas modernas, a diferencia de las sociedades antiguas en las que

${ }^{32}$ Zaccaria, G.: Razón jurídica e interpretación, op. cit., p. 28. No en vano este autor ha definido la hermenéutica jurídica como "un serio y original intento de reflexión sobre la relación concreta de la norma jurídica con el segmento de la realidad regulado por su ámbito de aplicación”, p. 28 de esa misma obra.

33 Sentencia del Tribunal Constitucional 185/1989, fundamento jurídico $4^{\circ}$.

34 Zaccaria, G.: Razón jurídica e interpretación, op. cit., p. 34. 
el órgano creador del derecho era el único legitimado para interpretarlo ${ }^{35}$, es posible proceder a un control del razonamiento llevado a cabo por los órganos judiciales a la hora de aplicar las normas o del legislador cuando las tiene que elaborar. En el caso de los derechos fundamentales "en la medida en que tienen el carácter de derechos del particular frente al legislador, son posiciones que, por definición, fundamentan deberes del legislador y limitan sus competencias". Es más, "si la Constitución garantiza al individuo derechos frente al legislador y (también) para la garantía de estos derechos prevé un Tribunal Constitucional, entonces la intervención del Tribunal Constitucional en el ámbito de la legislación, necesaria para la garantía de estos derechos, no es una asunción anticonstitucional de las competencias legislativas, sino algo que no sólo está permitido sino también ordenado por la Constitución" 36 . Por tanto, "la Constitución y la justicia constitucional se conciben como artificios jurídicos que cobran todo su sentido al servicio de la limitación del poder y de la garantía de la inmunidad y libertad de las personas" 37 .

En estas posiciones percibimos una tendencia a rechazar la idea de autoridad de determinadas instituciones cuando se utiliza como excusa para evitar un adecuado control de la actuación de los órganos judiciales establecido a partir de la configuración del Estado de derecho y de la división de poderes, de ahí que aboguen por un control constitucional en la elaboración y aplicación de las normas.

b) La otra cara de la moneda representa una posición favorable no sólo a la idea de autoridad, sino que introduce otros elementos como la continuidad, el desarrollo del derecho y la equidad a la hora de valorar la interpretación jurídi$\mathrm{ca}^{38}$. Sin embargo es la autoridad y la continuidad lo que da sentido a la pregunta por qué interpretar. La continuidad, que es inherente en el derecho, se manifiesta en el hecho de que las normas y los precedentes permanecen inalterados después de que sus autores ya no estén en el poder. Por tanto, se debería interpretar de tal forma que la interpretación responda a las razones que tenemos para

35 De hecho, tal y como señala F. J. Ezquiaga Ganuzas, en esta época "no se exigía la motivación de la sentencia y, por tanto, no era posible realizar ningún control institucional ni social sobre la actividad aplicativa o interpretativa de las normas": La argumentación en la justicia constitucional española. Instituto Vasco de Administración Pública. Oñate, 1987, p. 27.

36 Alexy, R.: Teoría de los derechos fundamentales. Centro de Estudios Políticos y Constitucionales, Madrid, 2002, p. 527.

37 Prieto Sanchís, L.: Justicia constitucional y derechos fundamentales, Trotta, Madrid, 2003, p. 9.

$38 \mathrm{~J}$. Raz afirma que en la interpretación jurídica valoramos la continuidad, la autoridad, el desarrollo jurídico y la equidad. Asimismo aclara que "hay dos tipos de factores que estarán siempre en conflicto: autoridad y continuidad militan hacia una actitud conservadora en la interpretación, equidad y desarrollo jurídico hacia una actitud innovadora. Esta tensión - de una u otra forma- es típica de toda interpretación. Entender esto, y sus fuentes, está en el centro del entendimiento de lo que hace que la interpretación sea lo que es": Raz, J.: "Why Interpret?", op. cit., p. 361. 
interpretar. Autoridad y continuidad aportan las justificaciones para dirigir el razonamiento jurídico como un razonamiento interpretativo así como contribuyen a la determinación de su carácter, y la equidad y el desarrollo del derecho no son razones en absoluto para interpretar, pero tenemos razones para entender que contribuyen a la determinación de su carácter. La necesidad de continuidad juega un papel similar en el razonamiento legislativo, sin darle carácter interpretativo. Es solamente en combinación con el respeto de los tribunales a la autoridad lo que sostiene el razonamiento interpretativo ${ }^{39}$.

Entendemos que la idea de autoridad que maneja Raz está lejos de ser una obediencia a ciegas, ni tampoco supone sumisión o abdicación de la razón por parte del intérprete. En sus palabras subyace más bien la expresión del reconocimiento hacia otros, en este caso hacia la autoridad o autoridades. A su vez el reconocimiento, no es sumisión sino una delicada forma de conocimiento. Esta forma de entender el reconocimiento de la autoridad no excluye entender el derecho como una orden o mandato del soberano, ni el esquema de verticalidad en el que se encuadra, tal y como proclama la Jurisprudencia Analítica. Lo que revela es en qué medida el intérprete tiene que contribuir con la autoridad. Esa colaboración tiene que ver, en primer lugar, con el conocimiento: así, el criterio de la autoridad - del legislador -se puede decir- precede al juicio del intérprete y tiene prioridad respecto a sus propias opiniones y juicios. Además, la autoridad representa el conocimiento y el intérprete reconoce que necesita ese conocimiento de la autoridad y, por tanto, acepta su orden. Ese reconocimiento a la autoridad no es a alguien en particular en un momento determinado, puesto que ello conllevaría su desaparición una vez que esa persona ya no ejerciera la autoridad, sino que se refiere a lo que esa persona representa; una institución y, con ella, una autoridad. De hecho, la tradición se ha ido formando por una continuada sucesión de culto a la autoridad -aunque sea anónima- y que ha ido inspirando el trabajo diario de los intérpretes. Es la tradición formada por el conjunto de las decisiones jurídicas y su argumentación lo que aporta al jurista un acervo de conocimiento nada desdeñable. A su vez, el que interpreta también tiene que estar revestido de un cierto grado de autoridad, aunque sea diferente de la que tiene quien emite las órdenes, con el fin de que el resultado de su interpretación sea aceptada por los destinatarios. Como si estuviera inmerso en una cadena, el intérprete interpreta porque reconoce la autoridad - y el conocimiento- que tiene quien elabora o ha elaborado las normas y, a su vez, porque está revestido de capacidad para interpretar. Esta concepción de la autoridad explica a su vez la continuidad del derecho. El derecho habría desaparecido si no hubiera intérpretes dispuestos a pasar por el camino que culmina en su aplicación ${ }^{40}$.

${ }^{39}$ Raz, J.: “Why Interpret?”, op. cit., pp. 357, 358, 360, y 361. Cursiva nuestra.

40 Galán Juárez, M.: Command as Metaphor. (A Philosophy of Analytical Jurisprudence). Dilex, Madrid, 1999, pp. 98-103. 
En el contexto de la interpretación de los derechos fundamentales por parte del Tribunal Constitucional, se puede apreciar que la razón de autoridad juega un papel decisivo. La declaración de derechos contenida en la Constitución Española es uno de los pilares sobre los que se asienta nuestro Estado de derecho y que el Tribunal Constitucional se encarga de garantizar. Su jurisprudencia representa una doctrina revestida de gran autoridad que ha ido creciendo a lo largo del tiempo, si bien ha discurrido paralela a los conflictos de competencias con el Tribunal Supremo ${ }^{41}$.

2.3. La tercera razón la aporta la relativa indeterminación y fragmentariedad de los preceptos constitucionales en los que no suele ser reconocible la dualidad supuesto de hecho/consecuencia jurídica. En el caso de las normas constitucionales que contienen el reconocimiento de derechos fundamentales, es todavía más evidente, de ahí que la delimitación del contenido constitucional de los derechos sea una de las tareas más importantes y complejas que debe llevar a cabo el intérprete jurídico ${ }^{42}$. De hecho, una de las principales dificultades que se plantean al garantizar el efectivo disfrute de un derecho fundamental consiste en identificar la regla aplicable ante un caso concreto: ello en la medida en que la idea histórica del juez como "boca de la ley", la concepción del juez como mero ejecutor de la voluntad del legislador mal se adecua a la realidad actual ${ }^{43}$.

\section{3. ¿Cómo hay que interpretar los derechos fundamentales contenidos en las normas constitucionales?}

Una vez respondida la pregunta de por qué interpretar, podemos abordar la cuestión de cómo hacerlo ${ }^{44}$. En efecto, las razones de autoridad, continuidad, necesariedad, la propia naturaleza de las normas y, sobre todo, el logro del mejor derecho

41 Galán Juárez, M.: Intimidad. Nuevas dimensiones de un viejo derecho. Editorial Universitaria Ramón Areces y Servicio de Publicaciones Universidad Rey Juan Carlos, Madrid, 2005, p. 161: En relación con la ponderación de derechos fundamentales realizada por el Tribunal Constitucional "el Tribunal Supremo acusa al Tribunal Constitucional de sobrepasar los límites propios de la jurisdicción de amparo, para entrometerse en la función propia y exclusiva de los órganos judiciales que les atribuye el artículo 117.3 de la Constitución Española.

El Tribunal Supremo ha mantenido en reiteradas ocasiones que el Tribunal Constitucional debería limitarse a apreciar si hubo o no vulneración del derecho fundamental de que se trate y, en caso afirmativo, devolver el asunto al órgano jurisdiccional que conoció del mismo para que realice un nuevo pronunciamiento, esta vez ajustado a la valoración hecha por el Tribunal Constitucional".

42 Martínez-Pujalte, A-L.: "Toda interpretación jurídica debe ser una respuesta a problemas concretos", en <http://www.bahaidream.com/lapluma/derecho/revista004/interpretacion.htm>

43 Rolla, G.: "Técnicas de codificación y cláusulas de interpretación de los derechos fundamentales. Algunas consideraciones a propósito de la carta de derechos fundamentales de la Unión Europea", en Revista de Derecho Constitucional Europeo. Año 2, número 4, Julio-diciembre 2005: <http://www.ugr.es/redce/REDCE4/articulos/03rolla.htm>

44 Recordemos que J. Raz sostenía que la pregunta de por qué interpretar no podía ser respondida sin la del cómo interpretar: "Why Interpret?", op. cit., p. 351. 
posible, expuestas en el apartado anterior, deberían constituir justificación suficiente para plantear la forma de llevar a cabo la interpretación. Es más, son esos motivos lo que condicionan el cómo en la medida que si no se tiene en cuenta el fin último, el por qué de la interpretación, cualquier manera de realizarla sería válida pero no necesariamente comprometida con el fin del derecho. Si bien la interpretación es una labor necesaria y, en todo caso, ineludible e inevitable, no sirve a su fin si actúa al margen de las razones que la inspiran. De ahí que ambas cuestiones estén íntimamente conectadas.

Vamos a proceder a determinar los parámetros en los que se mueve la actividad interpretativa y con ello dar respuesta a la pregunta planteada:

3. 1. En primer lugar, a la hora de interpretar una norma hay que tener en cuenta que los criterios tradicionales que enuncia el artículo 3.1 del Código civil pueden y deben ser aplicados no sólo en la interpretación en general sino también en la interpretación de las normas constitucionales.

3. 2. No podemos olvidar tampoco la relevancia que tiene en el discurso interpretativo la mirada hacia el marco en el que la norma se encuadra. De hecho, "el discurso jurídico se funda y se expresa en comunidades de interpretación y argumentación que existen concretamente, en las que objeto de intercambio y de interacción intersubjetiva son experiencias reales y convicciones relativas a 'cosas', que son refutadas, modificadas o confirmadas. Las mismas normas - como bien ha demostrado, entre otros Ricoeur- no pueden estar desvinculadas del contexto, de la situación y de una conexión histórico-particular efectiva, sino que necesariamente tiene que medirse con su 'valer' en la vida". (...) Dado que toda aplicación de las normas parte forzosamente de un contexto determinado, o sea, de una situación concreta y de un ámbito de vida común en el que las acciones individuales poseen y precisan un significado propio, será necesario también que el intérprete tenga verdaderamente en cuenta, de una manera precisa, todos los aspectos relevantes que connotan esta situación" 45 .

\section{3. La interpretación "conforme a la Constitución"}

$\mathrm{Al}$ comienzo de nuestra exposición, cuando señalábamos las distintas acepciones de interpretación, ya adelantábamos que la que hacía referencia a la "búsqueda de entre los varios entendimientos posibles de una regla de Derecho aquella opción que mejor se acomode a los dictados constitucionales" era la que más se adecuaba al objeto de nuestro trabajo. Esa acepción podría ser calificada más como una orientación preferente sobre cómo interpretar que como un criterio de

${ }^{45}$ Zaccaria, G.: Razón jurídica e interpretación, op. cit., pp. 51 y 56. 
interpretación más que se añadiría a los ya clásicos histórico, sistemático, lógico, etc. ${ }^{46}$. Es en este estadio de la exposición donde cobra sentido la opción manifestada y donde se conecta con la primera forma de interpretación esgrimida en líneas superiores. La interpretación "conforme a la Constitución” no sustituye al mandato del artículo 3.1 del Código civil ya que previamente se ha tenido que haber dado la interpretación legal según los cánones tradicionales que enuncia este artículo. La "interpretación conforme" se tiene que mover en primera instancia dentro de los parámetros marcados por el artículo 3.1 del Código civil, puesto que actuar al margen de ellos supondría incurrir en un cambio judicial de la ley amparándose en la excusa del cumplimiento de la Constitución. La justificación de este modo de operar la encontramos en el artículo 9 de la Constitución Española en su apartado primero y tercero al proclamar respectivamente la sujeción de los poderes públicos a la Constitución y al resto del ordenamiento jurídico y la garantía que hace la Constitución del principio de legalidad, jerarquía normativo o la interdicción de la arbitrariedad de los poderes públicos, entre otros. Por tanto, la "interpretación conforme", lejos de engrosar la lista de los criterios de interpretación supone una manifestación de uno de ellos, el criterio sistemático, y se justifica en la unidad del ordenamiento jurídico y en la primacía de la Constitución, de tal manera que el producto del proceso hermenéutico, es decir, la resolución judicial, concuerde lo más posible con lo que la Constitución prescribe. En el caso de la interpretación de los derechos fundamentales, se deberá hacer teniendo en cuenta la máxima eficacia posible a los derechos fundamentales que han sido objeto de conformación legislativa ${ }^{47}$.

\subsection{El artículo 10.1 de la Constitución Española}

En el apartado anterior veíamos cómo la idea de la unidad del ordenamiento jurídico y la primacía de la Constitución permitían dar sentido a la interpretación de los derechos fundamentales, que en todo caso se debería hacer "conforme a la Constitución". Esa remisión a la Constitución nos aporta de nuevo la clave para seguir respondiendo a cómo interpretar. Es la propia Constitución la que esgrime algunas pautas de interpretación con el fin de lograr el equilibrio que corresponde tanto al legislador como al intérprete competente para la solución del caso. En el caso de nuestra Constitución esa cláusula estaría ubicada en su artículo 10 que al proclamar "la dignidad de la persona, los derechos inviolables que le son inherentes, el libre desarrollo de la personalidad y el respeto a la ley y a los derechos

\footnotetext{
${ }^{46}$ En este sentido señala K. Hesse que "la interpretación conforme tampoco supone la operatividad de un nuevo criterio hermenéutico. (...) la interpretación conforme sólo puede entenderse de modo acertado como una concreción magnífica del criterio sistemático, impuesta por la supremacía de la Constitución y, en último término, por tanto, por la unidad del ordenamiento jurídico: "La interpretación constitucional", en Escritos de Derecho Constitucional, traducción de Pedro Cruz Villalón, Centro de Estudios Constitucionales, Madrid, 1992, pp. 31-57, en concreto pp. 51 y 54.

47 Sentencia del Tribunal Constitucional 93/1984, de 16 de octubre.
} 
de los demás son el fundamento del orden político y de la paz social" delimita el ámbito de la actividad interpretativa. Ésta tiene que moverse dentro de los márgenes que marca el contenido de este artículo, especialmente el respeto a la ley y a la conjugación de los derechos de unas personas con los de otras. Podríamos decir que estos dos elementos constituyen el techo de su actuación mientras que la base sobre la que se sustenta se dirige más hacia la particularidad del individuo: la dignidad de la persona, los derechos inviolables que le son inherentes y el libre desarrollo de su personalidad. Una interpretación contraria a estos dictados constitucionales quebraría el orden político y la paz social. Hay quien además percibe que este tipo de cláusulas hacen más hincapié en la vertiente del reconocimiento de derechos que en su ponderación "en el sentido de que intentan calificar los elencos de derechos contenidos en la Carta como parcialmente 'abiertos' o 'dinámicos', capaces de consentir una interpretación evolutiva de las disposiciones constitucionales en materia de derechos". Asimismo "la inserción de dichas cláusulas autoriza, más bien, una interpretación dinámica de las posiciones subjetivas expresamente reconocidas, permite considerar como fundamentales no sólo los derechos reconocidos de manera explícita por la Constitución, sino también aquéllos que pueden recavarse de forma explicita, instrumental o transversal, siempre que sean reconducibles bajo el principio personalista" ${ }^{48}$.

\section{5. El artículo 10. 2 de la Constitución Española}

Lejos de dejar a un lado la Constitución, volvemos a leer en ella otra cláusula de interpretación especialmente válida y reiteradamente utilizada por el Tribunal Constitucional ${ }^{49}$. Así, la Constitución Española declara en su artículo 10.2 un sistema de conexión entre, por una parte, los derechos fundamentales y libertades que ella reconoce y, por otra parte, los Convenios y Tratados Internacionales ratificados por España ${ }^{50}$ estableciendo que los primeros se interpretarán a la luz de

\footnotetext{
48 Rolla, G.: "Técnicas de codificación y cláusulas de interpretación de los derechos fundamentales. Algunas consideraciones a propósito de la carta de derechos fundamentales de la Unión Europea”, en Revista de Derecho Constitucional Europeo. Año 2, número 4, Julio-diciembre 2005: http://www.ugr.es/redce/REDCE4/articulos/03rolla.htm. Op. cit. Asimismo señala este autor que la Carta de derechos fundamentales de la Unión no contiene disposición explícitamente asimilable a citada española, aunque "la centralidad del principio personalista emerge tanto del Preámbulo de la Carta, donde 'la Unión (...) sitúa a la persona en el centro de su actuación', creando 'un espacio de libertad, seguridad y justicia', como reenvío dinámico que en el mismo se contiene con respecto a las tradiciones constitucionales comunes a los Estados miembros y al Convenio para la Protección de los Derechos Humanos y de las Libertades Fundamentales".

49 El Tribunal Constitucional ha aplicado este tipo de argumento refiriéndose al derecho comparado o a la legislación extranjera de forma genérica (Sentencia del Tribunal Constitucional 57/1982, de 27 de julio, fundamento jurídico $9^{\circ}$ ) o señalando concretamente el ordenamiento jurídico que utiliza como modelo (Sentencia del Tribunal Constitucional 73/1983, de 30 de julio, fundamento jurídico $7^{\circ}$ ).

50 Asimismo señala Rolla, refiriéndose a la Carta de derechos fundamentales de la Unión, que en ella no faltan cláusulas asimilables, en un cierto sentido, a la del artículo 10.2 de la Constitución Española. Así el artículo 112.3 dispone que "en la medida que la presente Carta contenga derecho que corresponda a derechos
} 
los segundos. Esta forma de interpretación ha recibido el nombre de "argumento comparativo", que es un tipo de apelación a la regulación establecida por otros sistemas jurídicos debido a la "autoridad" que representan ${ }^{51}$. Se ha señalado asimismo que "el llamado 'quinto método', traducido relativamente en nuestro sistema en el artículo 10.2 de la Constitución, no es sino otra manifestación del criterio sistemático (respecto de las normas relativas a los derechos fundamentales y a las libertades que la Constitución reconoce), toda vez que los Tratados internacionales forman parte del ordenamiento interno, una vez publicados (...). Este artículo 10.2 es sólo un reflejo 'internacionalista', pues es el recurso a derechos ajenos (al menos inicialmente) al derecho interno, junto con su manifestación sistemática, su único parecido, ya que ese precepto impone una 'interpretación conforme' que no es la propiciada por el 'quinto método', de sentido comparatista"52.

\subsection{La argumentación encaminada a la interpretación de la Constitución en términos de razonabilidad}

Llegados a este punto en la reflexión sobre cómo interpretar los derechos fundamentales, nos encontramos con la labor que da sentido al contenido de la resolución adoptada. No se trata de un nuevo criterio interpretativo, o directiva sobre la interpretación, o regla argumental 53 sino que representa un "principio ordenador de la argumentación jurídica, tanto en el momento de la decisión como en el de su justificación" 54 . Esta forma de argumentación se concreta cuando "el intérprete, en una valoración en parte lógica y en parte ligada a valores, sopesa las consecuencias de una decisión jurídica. Tales consecuencias pueden referirse a los efectos de la decisión sobre el mundo real, sobre el mundo jurídico y, por último, a su cohesión con valores extrajurídicos". Hassemer advierte, sin embargo, del

garantizados por el Convenio Europeo para la Protección de Derechos Humanos y de las Libertades Fundamentales, su sentido y alcance serán iguales a los que les confiere dicho Convenio...". Igualmente es relevante en este sentido el contenido del artículo 113 del mismo texto.: "Técnicas de codificación y cláusulas de interpretación de los derechos fundamentales. Algunas consideraciones a propósito de la carta de derechos fundamentales de la Unión Europea", en Revista de Derecho Constitucional Europeo. Revista de Derecho Constitucional Europeo, op. cit.

51 Ezquiaga Ganuzas, F. J.: La argumentación en la justicia constitucional española, op. cit., p. 325 y ss. Asimismo señala que son numerosas las sentencias del Tribunal Constitucional que hacen referencia a los Tratados y esta referencia se ha convertido en un argumento habitual de los recurrentes como apoyo de sus pretensiones -especialmente en materia laboral (libertad sindical, jubilación, huelga, etc.) y judicial o de garantías procesales (justicia militar, derecho del acusado a la defensa, etc.). De hecho, la extraordinaria fuerza retórica que ha adquirido la referencia al ordenamiento internacional es debido al grado de autoridad del que están investidas las organizaciones internacionales: p. 328.

52 Requena López, T.: Sobre la función, los medios y los límites de la interpretación de la Constitución, op. cit., p. 85. Asimismo añade en la p. 86 que "el artículo 10.2 recuerda la existencia de un mínimo contenido constitucional de los derechos fundamentales compartido culturalmente y que de ningún modo puede mudarse".

53 Requena López, T.: Sobre la función, los medios y los límites de la interpretación de la Constitución, op. cit., p. 91.

54 Zaccaria, G.: Razón jurídica e interpretación, op. cit., p. 58. 
"error de limitar la racionalidad a lo puramente inteligible. Esta identificación apresurada de lo racional con lo científicamente inteligible simplemente contradice la realidad y, por lo tanto, hay que rechazarla a su vez como irracional. En efecto, la realidad nos presenta un conjunto no divisible de factores racionales y a-racionales, de postulados de racionalidad y de postulados de valor. En la realidad, y en particular en la realidad jurídica, lo racional se combina y se entrelaza con lo irracional". Como consecuencia, "podrá considerarse racional, en la acepción de sensata, la acción que se somete a las condiciones públicas de aceptabilidad fijadas por una determinada comunidad axiológica y lingüística" 55 .

"Con la razonabilidad se describe el contenido argumental y más precisamente una característica de la decisión o decisiones adoptadas" 56 , en este caso, en materia de derechos fundamentales. Responde directamente a la pregunta práctica de cómo se debe argumentar de tal modo que la argumentación no sólo sea "conforme a la Constitución", en su sentido más técnico, ni vulnere el artículo 10 de la Constitución, sino que le de un sentido al deber-ser de los derechos fundamentales. Es más, será como consecuencia de una argumentación en términos de razonabilidad cuando se consiga un resultado constitucionalmente correcto y la interpretación adquiera la forma constitucional exigida y que hemos expuesto en los apartados anteriores. De ahí que cuando el citado artículo 9.1 de la Constitución Española prescribe el sometimiento de los poderes públicos -además de los ciudadanos- a la Constitución significa que su actuación no puede estar motivada por su voluntad de buscar una única solución correcta, sino por la obligación de decidir en términos susceptibles de argumentación racional ${ }^{57}$. Esa decisión en términos racionales dará como resultado que el derecho que de ella emane será un derecho nuevo en el sentido de que el juez o el tribunal - en el caso de las resoluciones judiciales - habrá contribuido a darle una forma concreta. No olvidemos, de hecho, lo que señalábamos en líneas superiores cuando reproducíamos las afirmaciones de que el derecho es el resultado de la interpretación (Robles), que la interpretación es constitutiva del derecho (Dworkin) y que algo hay que aprender acerca de la naturaleza del derecho del hecho de que la interpretación juegue un papel tan crucial en la decisión del juez (Raz). Precisamente la combinación de estas afirmaciones da como resultado la confirmación de que la labor de interpretación, lejos de poner en riesgo la integridad de la norma constitucional, permite hacerla real y efectiva al motivar a los órganos jurisdiccionales a ejercer su función constitucional en un marco de "vínculo con la autoridad pero también ejercicio de responsabilidad"58,

55 Zaccaria, G.: Razón jurídica e interpretación, op. cit., p. 40, 46 y 59.

56 Requena López, T.: Sobre la función, los medios y los límites de la interpretación de la Constitución, op. cit., p. 91.

57 L. Prieto Sanchís aclara que "sin abandonar el terreno de la racionalidad, la Constitución admite distintas interpretaciones o, lo que es lo mismo, distintas teorías éticas o filosóficas políticas; no es patrimonio exclusivo de ninguna opción doctrinal": Justicia constitucional y derechos fundamentales, op. cit., p. 11.

58 Zaccaria, G.: Razón jurídica e interpretación, op. cit., p. 388. 
independencia, apertura ${ }^{59}$, pluralismo y respeto a la Constitución, que a su vez protege y garantiza su función. Sólo así será posible conjugar en las interpretaciones la pluralidad con la objetividad 60 , el subjetivismo ${ }^{61}$ y el legalismo, y se podrá seguir contribuyendo a la creación del mejor derecho posible que apunta hacia la justicia.

\subsection{Por medio del juicio de ponderación de los derechos fundamentales}

Donde quizás se manifieste de forma más evidente la razonabilidad con la que debe operar el intérprete constitucional es en el juicio de ponderación que realiza en la interpretación de los derechos fundamentales, especialmente cuando éstos operan como principios ${ }^{62}$. El propio proceso de ponderación es en sí mismo un ejercicio de racionalidad lo cual no significa que en cada caso conduzca a una única solución ${ }^{63}$. Existe tal vinculación entre ponderación y racionalidad que aunque el modo de resolver los conflictos entre principios recibe el nombre de ponderación, a veces se habla también de razonabilidad, proporcionalidad o interdicción de la arbitrariedad 64 .

La ponderación no es un nuevo método interpretativo ni una técnica interpretativa que se sume a las ya existentes ${ }^{65}$. Entendemos que no toda interpretación es

${ }^{59}$ Como explicaremos en el siguiente apartado referido a la ponderación, la apertura del sistema materialmente determinado por las normas iusfundamentales procede de la apertura de la ponderación. De esta manera, "el sistema jurídico tiene, en virtud de la vigencia de las normas iusfundamentales, el carácter de un sistema jurídico abierto cualquiera que sea la dimensión de esta apertura": Alexy, R.: Teoría de los derechos fundamentales, op. cit., p. 525.

60 Véase las reflexiones de J. Raz al respecto en "Why Interpret?", op. cit., p. 350 y 353.

$61 \mathrm{G}$. Zaccaria se hace eco de este subjetivismo cuando refiriéndose a la comprensión - como una de las acepciones de la interpretación -, reproduce las palabras de A. Kaufmann: "El comprender no es, en suma, ni objetivo ni puramente subjetivo, y no puede ser objeto de un conocimiento independiente del sujeto: el comprender es siempre también producto, aunque no exclusivo, del sujeto que conoce": Razón jurídica e interpretación, op. cit., p. 49.

62 De hecho, señala R. Alexy que "el carácter de principios de las normas iusfundamentales implica la necesidad de ponderaciones": Teoría de los derechos fundamentales, op. cit., p. 525.

Tal y como señalamos en nuestro libro Intimidad. Nuevas dimensiones de un viejo derecho, op. cit., p. 164: "Compartimos la opinión de que el modo de resolver los conflictos entre principios es una obligada ponderación. Esta afirmación esclarece la igualdad entre las normas en conflicto; dado que si no fuese así, por existir un orden jerárquico o de prelación que se pudiera deducir del propio texto normativo, la antinomia podría resolverse de acuerdo con el criterio jerárquico o de especialidad, sin la referida ponderación (Prieto Sanchís). En un caso estaríamos hablando de la resolución de antinomias entre normas, que desembocaría en la exclusión de una u otra; en el supuesto que nos interesa, nos referimos a la confluencia de dos principios que no son excluyentes sino que permiten delimitar el campo de aplicación de un derecho. Ahora bien, esa tarea de ponderación "ha de llevarse a cabo teniendo en cuenta la posición relevante, que no jerárquica o absoluta, que sobre los derechos denominados de la personalidad del artículo 18 Constitución Española ostentan los derechos a la libertad de expresión e información del artículo 20.1 de la Constitución Española (Sentencia del Tribunal Constitucional 49/1992 de 30 de marzo, fundamento jurídico $3^{\circ}$ )".

63 Alexy, R.: Teoría de los derechos fundamentales, op. cit., p. 525.

64 Prieto Sanchís, L.: Justicia constitucional y derechos fundamentales, op. cit., p. 189.

65 Requena López, T.: Sobre la función, los medios y los límites de la interpretación de la Constitución, op. cit., p. 92. 
subsunción pero sí toda interpretación de los derechos fundamentales -que actúan como principios-, es ponderación y, por tanto, la ponderación es un modo de interpretación. La subsunción respondería más a un procedimiento lógico mientras que la ponderación operaría a través de la racionalidad. Como consecuencia de ello, no comparto la posición de quien entiende que "la ponderación constituye siempre un ejercicio casuístico en el que hay que determinar cuidadosamente si los supuestos de hecho son subsumibles en los presupuestos jurídicos"66. Hay en esta afirmación más la aplicación silogística de una regla cerrada que la articulación de los principios que, por su naturaleza, no se excluyen sino que permiten delimitar el contenido de los derechos en juego y el campo de su aplicación. Eso sí que es un juicio ponderativo, tal y como establece el propio Tribunal Constitucional: "cuando del ejercicio a los derechos (...) resulten afectados otros derechos, el órgano jurisdiccional está obligado a realizar un juicio ponderativo de las circunstancias concurrentes en el caso concreto, con el fin de determinar si la conducta del agente está justificada por hallarse dentro del ámbito de las libertades de información y expresión"67. Asimismo, la utilización de la ponderación sería el mejor antídoto contra la arbitrariedad de los poderes públicos prohibida por el artículo 9.3 de la Constitución Española. Ahora bien, esta afirmación sólo cobra sentido si se entiende la ponderación como el ejercicio de racionalidad consistente en delimitar el ámbito de dos derechos en conflicto - cuando actúan como principios- basándose en el análisis de las circunstancias particulares y las causas que justifican la limitación de uno de ellos, respetando en todo caso su contenido esencial y las demás pautas constitucionales de ponderación. Precisamente el empleo de la razón jurídica obliga a renunciar a verdades absolutas ${ }^{68}$, lo que permite mantener una disposición de apertura para adentrarse en la casuística particular. Por el contrario, si se concibe la ponderación como "ejercicio casuístico en el que hay que determinar cuidadosamente si los supuestos de hecho son subsumibles en los presupuestos jurídicos" se la está confundiendo con la técnica de la subsunción, que no sería de plena utilidad para interpretar los derechos fundamentales cuando operan como principios. Si intentamos buscar la razón que lleva a algunos autores a entender la ponderación en términos de subsunción, podemos encontrarla en el argumento a favor de la no arbitrariedad de la actuación de

66 Pardo Falcón, J.: "Los derechos del artículo 18 de la Constitución Española en la Jurisprudencia del Tribunal Constitucional", en Revista Española de Derecho Constitucional, n 34, 1992, pp. 141-178, en concreto p. 176.

67 Sentencia del Tribunal Constitucional 204/1997 de 25 de noviembre, fundamento jurídico $2^{\circ}$. Para una exposición más amplia de esta cuestión ver Galán Juárez, M.: Intimidad. Nuevas dimensiones de un viejo derecho, op. cit., pp. 149-177.

${ }^{68} \mathrm{R}$. Alexy también afirma que "el procedimiento de ponderación es racional pero, no es un procedimiento que en cada caso conduzca a exactamente una única solución. Cuál sea la solución que, después de una ponderación, es considerada como correcta depende de valoraciones que no son ellas mismas controlables a través del propio procedimiento de ponderación": Teoría de los derechos fundamentales, op. cit., p. 525 . 
los poderes públicos. En este sentido se afirma que la ponderación, concebida como ejercicio de racionalidad, es en el fondo una forma sutil de encubrir, y posiblemente justificar, una actuación arbitraria de los poderes públicos, de ahí que la mejor forma de evitarlo sea considerarla como un ejercicio de subsunción. Creemos que este punto de vista no es acertado porque, "la función dinámica del juez en la actividad de concreción del derecho, lejos de ser un trabajo arbitrario, está de algún modo vinculado a criterios de racionalidad"69. Además, al equiparar ponderación con arbitrariedad se pierde de vista una de las cuestiones centrales que hemos intentado resaltar a lo largo de este trabajo: por qué interpretar. La respuesta estaba en lograr a través de ella la configuración de un derecho lo más justo posible y sólo con la técnica de la ponderación se logra ese objetivo porque permite recabar el sentido exacto del alcance de los derechos fundamentales en juego atendiendo a cada caso particular y según un contexto determinado. Sólo así podremos llegar a conocer la verdadera naturaleza jurídica de los derechos fundamentales, tal y como sugeriría Raz.

Otro argumento a favor de la ponderación está en que la propia Constitución previene contra cualquier posible arbitrariedad al establecer unas cláusulas para la ponderación de los derechos. Esas cláusulas pueden ser de dos tipos, según introduzcan una técnica de interpretación o bien individualicen un valor sobre la base del cual pueda operar la ponderación. Pertenecen a la primera tipología las disposiciones constitucionales que se refieren al principio de proporcionalidad o bien al contenido esencial de los derechos; la segunda tipología está constituida por cláusulas que aluden a la dignidad humana, a lo que es necesario en una sociedad democrática o bien otras fórmulas parecidas ${ }^{70}$.

Además, esta técnica permite mantener el dinamismo del sistema de interpretación constitucional e ir adaptando la Constitución a las nuevas circunstancias y realidades sociales ${ }^{71}$. Muestra de ello es que la doctrina del Tribunal Constitucional

69 Zaccaria, G.: Razón jurídica e interpretación, op. cit., p. 383.

70 Rolla, G.: "Técnicas de codificación y cláusulas de interpretación de los derechos fundamentales. Algunas consideraciones a propósito de la carta de derechos fundamentales de la Unión Europea", en Revista de Derecho Constitucional Europeo. Año 2, número 4, Julio-diciembre 2005: http://www.ugr.es/redce/REDCE4/articulos/03rolla.htm, op. cit.

${ }^{71}$ Un ejemplo de ello lo encontramos en el cambio paulatino de doctrina del Tribunal Constitucional en relación con la ponderación de los derechos del artículo 18.1 y 20.1 a) y d) de la Constitución: mientras que en sus primeras sentencias, nacidas en un marco socio-político de recién estrenada democracia, solía ponderar más a favor de los derechos del artículo 18.1 - sobre todo en el caso de que el derecho al honor estuviera en juego- en las últimas sentencias la querencia doctrinal ha tendido a ser la opuesta asentándose cada vez más el principio pro libertatis y, por tanto, a favor de las garantías institucionales que representan los derechos contenidos en el artículo 20.1 a) y d) de la Constitución. F. Herrero Tejedor se ha hecho eco de esta observación cuando, al referirse al "recurso de amparo en el conflicto de derechos honor-libertad de expresión" opina que la doctrina del Tribunal Constitucional ha pasado por tres etapas: 1- Identificar la tutela del derecho al honor (o a la intimidad o la imagen en su caso) con el derecho a la tutela efectiva de jueces y tribunales. 2- Obligar a los órganos judiciales a efectuar una "necesaria y casuística ponderación" de los derechos fundamentales en pugna, para respetar el resultado de la misma. 3- Atribuirse directamente la valoración de la ponderación efectuada por los tribunales ordinarios: Honor, intimidad y propia imagen. Colex, Madrid, 1990, pp. 308-312. 
ha ido evolucionando en los veinticinco años de historia constitucional a pesar de que la Constitución haya permanecido inalterada durante ese tiempo. En todo caso podemos confirmar que el juicio de ponderación es el método propio para determinar, cómo, cuándo y hasta qué punto debe ceder el derecho fundamental que entra en colisión con otro o con un bien. De ahí que se haya convertido en el medio ineludible que tienen los magistrados del Tribunal Constitucional para determinar cuestiones prácticas de la aplicación de los derechos y libertades fundamentales, tal y como les exigen habitualmente los recursos de amparo ${ }^{72}$. Asimismo, la ponderación es tratada fundamentalmente como técnica utilizada por el Tribunal Constitucional y los tribunales ordinarios en los conflictos entre las libertades de expresión e información y otros derechos, particularmente los derechos al honor, a la intimidad personal y familiar y a la propia imagen. Ese ha sido el contexto en el que por diversas razones se ha configurado a la ponderación como técnica interpretativa especial de la interpretación constitucional73.

\section{Conclusión}

Entendemos que la acepción de interpretación que señalábamos al comienzo de este trabajo como la búsqueda de "entre los varios entendimientos posibles de una regla de Derecho" aquella opción "que mejor se acomode a los dictados constitucionales", es la que encajaría en la interpretación de los derechos fundamentales contenidos en la Constitución Española, puesto que son los propios dictados constitucionales (artículo 9.3) los que han prohibido la "arbitrariedad de los poderes públicos", que se consigue con la ponderación de los derechos en juego por medio de una argumentación en términos de razonabilidad. Sólo así se podrá "hacer lo mejor del objeto de la interpretación"74, contribuyendo a la construcción del derecho más justo posible. Precisamente la exigencia del propio derecho de expandir la idea de justicia en todos los ámbitos del derecho se realiza por medio del respeto a los derechos fundamentales.

72 Martín-Retortillo Baquer, L. y de Otto y Pardo, I.: "La regulación del ejercicio de los derechos y libertades. La garantía de su contenido esencial en el artículo 53 de la Constitución”, en Derechos fundamentales y Constitución, Civitas, Madrid, 1988, p. 111.

73 Requena López, T.: Sobre la función, los medios y los límites de la interpretación de la Constitución, op. cit., p. 92.

${ }^{74}$ Dworkin, R.: “Law, Philosophy and Interpretation”, en ARSP, Vol. 80, 4, 1994, pp. 463-475, en concreto p. 473. 